OPEN ACCESS

Edited by: Gerardo Avalos,

University of Costa Rica, Costa Rica

Reviewed by:

Michael Kessler,

University of Zurich, Switzerland

Heidi Renninger,

Mississippi State University,

United States

${ }^{*}$ Correspondence:

William Truillo

williamtrujilloca@gmail.com

Specialty section:

This article was submitted to

Forest Ecophysiology,

a section of the journal

Frontiers in Forests and Global

Change

Received: 10 June 2021

Accepted: 25 August 2021

Published: 24 September 2021

Citation:

Trujillo W, Rivera-Rondón CA and Balslev H (2021) Palm Functional

Traits, Soil Fertility and Hydrology

Relationships in Western Amazonia.

Front. For. Glob. Change 4:723553.

doi: 10.3389/ffgc.2021.723553

\section{Palm Functional Traits, Soil Fertility and Hydrology Relationships in Western Amazonia}

\author{
William Trujillo ${ }^{*}$, Carlos A. Rivera-Rondón² and Henrik Balslev ${ }^{3}$ \\ ${ }^{1}$ Grupo Investigaciones Territoriales Para el Uso y Conservación de la Biodiversidad, Fundación Reserva Natural La Palmita, \\ Centro de Investigación, Bogotá, Colombia, ² UNESIS, Departamento de Biología, Pontificia Universidad Javeriana, Bogotá, \\ Colombia, ${ }^{3}$ Department of Biology, Ecoinformatic and Biodiversity, Aarhus University, Aarhus, Denmark
}

Quantification of multivariate trait spectra (or axes of specialization) make the definition of plant strategies more operational, which promotes trait-based theory of community assembly and the understanding of dynamics and functioning of ecosystems. We used field-quantified soil data to explore trait-environment relationships across palm communities in western Amazonia. We collected data from 116 palm species in 458 transects across four distinct forest types. We combined these data with trait records to relate local plant community trait composition to broad gradients in soil variables and forest types. There were significant trait-environment relationships across western Amazonia. Palms with large leaves and fruits, and palms with both growth forms (acaulescent/erect) were associated with fertile soils, while palms with unarmed leaves and stems were associated with non-inundated environments. These results suggest that the functional traits of palms vary consistently along soil gradients on a regional scale. This variation could be explained by the soil fertility and acidity + aluminum gradients, suggesting environmental filters related to resource availability and stressful environments, such as acid soils and soils with high aluminum content.

Keywords: floodplain, functional ecology, terra firme, soil properties, South America

\section{INTRODUCTION}

The most functional plant traits reflect adaptations to environmental conditions found in their immediate proximity (Díaz et al., 2016). Life-history evolution has produced distinct plant strategies that are positioned along the fast-slow trait spectrum and leaf-height-seed strategy (Westoby, 1998). Given the important roles of soil microbes in both nutrient acquisition and plant disease, we should expect relationships between plant-soil feedbacks and the plant strategies traditionally linked with functional traits (Xi et al., 2021). Plant-soil feedbacks express how plants interact with soil microbes and soil biogeochemical and physical properties (Van der Putten et al., 2013). For example, plants can invest in traits that promote rapid growth (via nutrient acquisition) or in traits that provide defense against antagonists (Díaz et al., 2016). Plant height may indicate plant life span and competitive ability for light (Moles et al., 2009).

The relationship between soil types and local and regional-scale palm community composition in lowland rain forest has been attributed to differences in soil fertility (Vormisto et al., 2004; Andersen et al., 2010). In lowland tropical rain forests the exchangeable bases, phosphorus (P) and 
nitrogen (N) explain palms and tree distributions (Clark et al., 1995; Phillips et al., 2003; Tuomisto et al., 2003a,b, Andersen et al., 2010; Baribault et al., 2012; Condit et al., 2013). Macronutrients such as $\mathrm{P}$ may be the most important limiting nutrient to tree growth (Vitousek, 1984). In northwestern Amazonia, Cámara et al. (2017) found that macronutrients, especially exchangeable bases $\left(\mathrm{Ca}^{2+}, \mathrm{K}^{+}\right.$, and $\left.\mathrm{Mg}^{2+}\right)$ and $\mathrm{P}$, emerged as more important than micronutrients in predicting species abundances in palm communities in non-inundated forests.

Studies of soil properties relative to plant traits have mostly focused on the importance of trait effect in driving soil properties and ecosystem functioning. Plant traits can influence soil microbial communities (Legay et al., 2014), soil abiotic properties (Reich, 2014), and nutrient cycling (Fortunel et al., 2009; Grigulis et al., 2013). Increasing plant functional trait diversity has been proposed as a potential mechanism to increase carbon allocation and storage below-ground (De Deyn et al., 2008). However, the relationship between soil properties and plant traits is bidirectional and have not been sufficiently incorporated into analyses that test for the importance of soil fertility as a driver of environmental filtering (Laughlin et al., 2015). Species and environmental conditions control community composition by selecting species with functional trait values that confer optimum fitness for those conditions (Keddy, 1992). Both structural and physiological leaf traits have been shown to correlate with soil nutrients at global scales (Maire et al., 2015). Plant traits can be rough proxies for ecosystem functioning and they respond to the biogeochemical and biophysical properties of ecosystems (Lavorel and Garnier, 2002; Wright et al., 2004).

Although plant-soil nutrient relationships have been studied extensively (see reviews by Chapin 1980, Aerts and Chapin 2000), the quantification of the response of traits through the nutrient gradient at different scales remains relatively unexplored (Ordoñez et al., 2009). Such quantitative knowledge is needed to advance our understanding of ecosystem functions, especially in the face of global change (Ordoñez et al., 2009). Here we investigated how palm traits are distributed in the forest types in western Amazonia and how they relate to soil properties. We hypothesized that the field-quantified environmental variables provide strong links with local trait composition.

\section{MATERIALS AND METHODS}

\section{Study Area}

On the largest spatial scale, Amazonia is characterized by a humid tropical climate with decreasing precipitation and increasing seasonality with increasing distance from the equator and toward the east (Silman, 2007). Soils in the western parts of the region have developed on Cenozoic sediments from the Andean orogeny, whereas soils in the east (e.g., on the Guyana shield) developed on Proterozoic crystalline bedrock (Sombroek, 2000). Within the western part of Amazonia (Figure 1), our 458 transects were sampled from four habitat types with 9-274 transects per habitat: non-inundated (Ninu) forest (274 transects: restinga 12 , terra firme 233 , and terrace 29), inundated forest (144 transects, floodplain), white-sand (9 transects), and pre-montane hills (PrH; 32 transects; Kristiansen et al., 2011; Eiserhardt et al., 2013; Balslev et al., 2019).

\section{Data Collection}

\section{Palm Species Distribution and Abundance Across the Western Amazon}

Collection of palm data on species presence/absence and abundance was carried out using a standardized transect methodology. Each transect was $5 \times 500 \mathrm{~m}(0.25 \mathrm{ha})$ and divided into 100 subunits of $5 \times 5 \mathrm{~m}$. In each transect subunit $(5 \times 5 \mathrm{~m})$, all individuals of palms were identified to the species level including seedlings, juveniles, subadults, and adults. A total of 458 transects ( $114.75 \mathrm{ha}$ ) with a total of 445,044 palm individuals were inventoried. Further details on the methodology can be found in Balslev et al. (2019).

\section{Environmental Variables}

In total, 11 soil variables were included in the analysis: $\mathrm{pH}$, loss-on-ignition (loi, a proxy for organic matter content), aluminum concentration $\left(\mathrm{Al}^{3+}\right)$, potassium concentration $\left(\mathrm{K}^{+}\right)$, exchangeable acidity (acidity, $\mathrm{H}+\mathrm{Al}$ ), base saturation (BS), calcium concentration $\left(\mathrm{Ca}^{2+}\right)$, sodium concentration $\left(\mathrm{Na}^{+}\right), \mathrm{P}$ concentration, effective cation exchange capacity (ECEC), and magnesium concentration $\left(\mathrm{Mg}^{2+}\right)$. Three soil samples were taken in each transect, one at each extreme and one in the center, and the three samples were averaged to obtain a single value per transect. The habitat type was registered in the transects (Forest Type; non-inundated $=$ nin, Inundated $=\mathrm{Inu}$, white sand $=\mathrm{WhS}$, and premontane hills $=\operatorname{PrH})$. More details about the units and variables can be obtained in Balslev et al. (2019).

\section{Palm Functional Traits}

The palm functional traits were obtained mainly from Kissling et al. (2019). We completed missing data with additional literature revision (Kahn and Ferreira, 1995; Borchsenius and Bernal, 1996; Henderson, 2000; Galeano and Bernal, 2010; Kahn and Millán, 2013). Thirteen functional traits were recorded for each palm species (Table 1). We used maximum fruit diameter as proxy for fruit size. In this study, fruit size was used as a proxy for the seed size, because several previous studies have demonstrated a positive correlation between fruit and seed size in fleshy-fruited plants, especially for single or few seeded fruits (Jordano, 2000).

\section{Data Analysis}

The continuous traits were categorized to show their distribution and frequencies among the forest types (Table 1). With the field data, three tables were constructed: matrix $Q_{(q \times m)}=13$ functional traits of 116 palm species (Table 1); matrix $R_{(n \times p)}=$ environmental variables of 458 transects; and matrix $L_{(n \times q)}=$ palm abundance in the 458 transects. Principal components analysis (PCA) was used to reduce the dimensionality of the environmental variables (11 soil variables) and to define the main variables that explain the variation among the sampled plots. A Fourth-Corner analysis (Dray et al., 2014) was used to evaluate the relationship of the species trait values with the environmental variables. Because there may be 


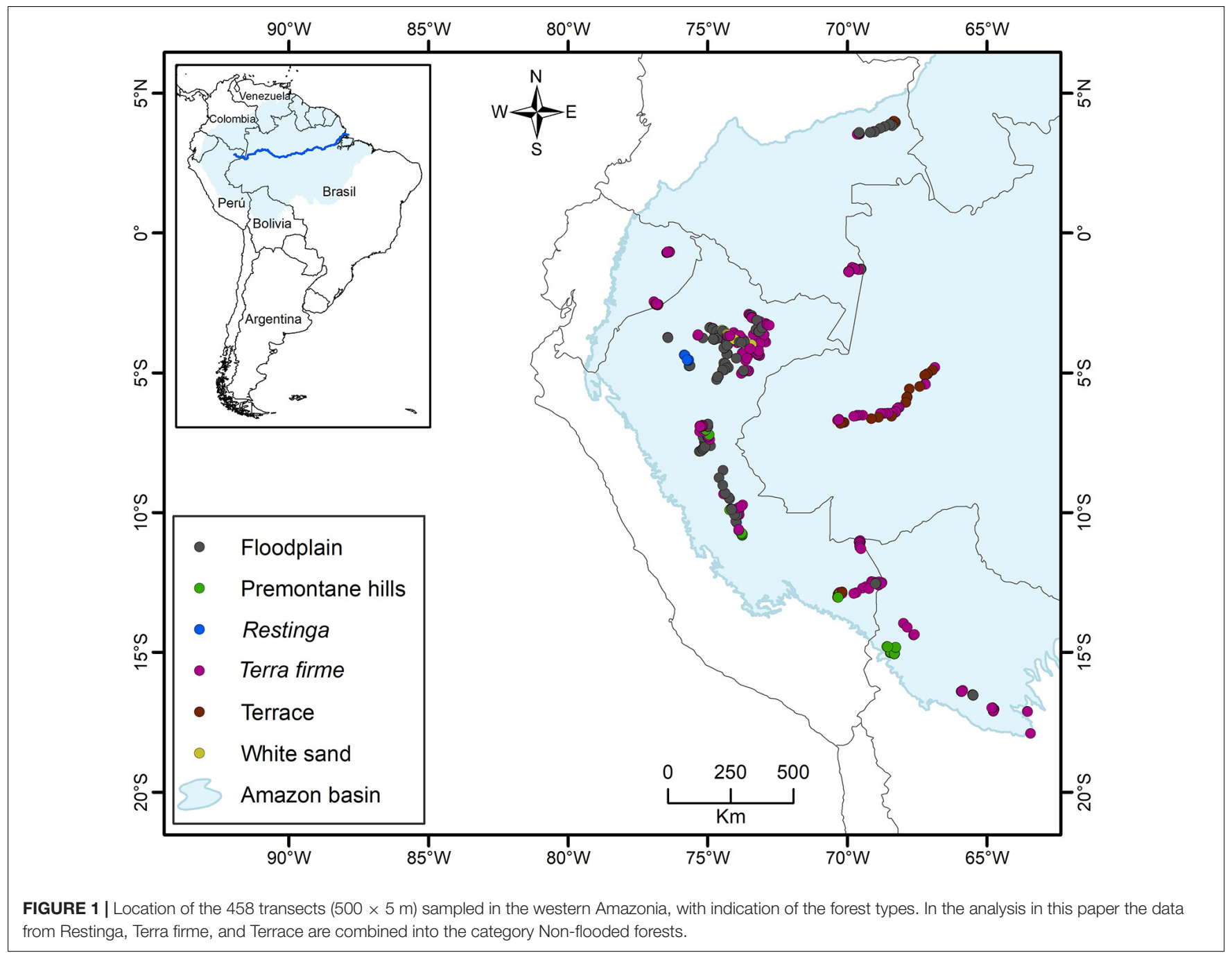

differences in the ecological responses of individuals according to their age, this analysis was carried out only using the data of adults (90,561 individuals). The Fourth-corner analysis tests the individual trait-environment relationship (Dray et al., 2014). We used the Model 6, which performs two separate tests using models 2 and 4 and to combine the results by keeping the higher $p$ value produced by the two permutation tests. The model 2 permutes the $\mathrm{n}$ samples (i.e., rows of $R$ or $L$ ) and model 4 permutes the $\mathrm{p}$ species (i.e., rows of $Q$ or columns of $L$ ). The Model 6 has the advantage of limiting the level of the type I error (Dray et al., 2014). Statistical analyses were carried out using R statistical software (R Core Team, 2016) and the Vegan (Oksanen et al., 2013) and Ade-4 packages (Dray and Dufour, 2007).

\section{RESULTS}

We recorded 116 palm species in the 458 transects that together encompassed a total of 114.75 ha. The most diverse genus was Bactris, with 27 species, followed by Geonoma (20), Astrocaryum (12), and Attalea (8). The most abundant species was Oenocarpus bataua, with 45,568 individuals, followed by Lepidocaryum tenue and Geonoma macrostachys, with 34,385 and 29,016 individuals, respectively.

Most palm individuals in western Amazonia (86\%) had erect growth forms. They were dominant in all of habitats (Figure 2A). Most individuals (43\%) were solitary and the cespitose life form were represented by $38 \%$ of the individuals; solitary palms were more abundant in premontane hills $(\mathrm{PrH})$, and the cespitose palms were evenly distributed between forests that were inundated (Inun), Ninu, on $\mathrm{PrH}$, and growing on white sands (WhS). Palms with both life forms (solitary/cespitose) were more abundant in WhS (Figure 2B). The highest proportion of individuals had short stems (54\%); but in forests growing on WhS tall palms were more abundant. Short palms $(0-8 \mathrm{~m})$ were evenly distributed between not-inundated (Ninu) and inundated (Inun) forests. Tall $(>18 \mathrm{~m})$ and medium tall palms $(9-17 \mathrm{~m})$ were more abundant in $\mathrm{PrH}$ and forests on white sand (WhS; Figure 2C). Similarly, most individuals (53\%) had small stem diameters $(0-10 \mathrm{~cm})$.

Most individuals (90\%) had few leaves (7-21). The individuals with medium numbers of leaves $(22-35)$ were more abundant in 
TABLE 1 | Functional traits of 116 palm species registered in western Amazonia.

\begin{tabular}{|c|c|c|}
\hline Traits & Categories & Trait type \\
\hline Lifeform (LF) & Cespitose $=$ ces, solitary $=$ sol & $\begin{array}{l}\text { Categorical, structural } \\
\text { trait }\end{array}$ \\
\hline Growth form (GF) & $\begin{array}{l}\text { acaulescent = aca, erect = ere, } \\
\text { climbing = cli }\end{array}$ & $\begin{array}{l}\text { Categorical, structural } \\
\text { trait }\end{array}$ \\
\hline Stem armed (StAr) & Unarmed = unar, armed = arm & Categorical, defense \\
\hline Leaves armed (Lar) & Unarmed = unar, armed = arm & Categorical, defense \\
\hline $\begin{array}{l}\text { Maximum stem } \\
\text { height }(\mathrm{StH})\end{array}$ & $\begin{array}{l}\text { Short }=0-8 \mathrm{~m} \\
\text { medium }=9-17 \mathrm{~m} \text {, tall = > } 18 \mathrm{~m} ;\end{array}$ & $\begin{array}{l}\text { Continuous, structural } \\
\text { trait }\end{array}$ \\
\hline $\begin{array}{l}\text { Maximum stem } \\
\text { diameter (StD) }\end{array}$ & $\begin{array}{l}\text { Small }=0-10 \mathrm{~cm}, \\
\text { medium }=10.1-20, \text { large }>20\end{array}$ & $\begin{array}{l}\text { Continuous, structural } \\
\text { trait }\end{array}$ \\
\hline $\begin{array}{l}\text { Maximum leaf } \\
\text { number }(\mathrm{LN})\end{array}$ & $\begin{array}{l}\text { Low }=7-21, \text { medium }=22-35 \\
\text { high }=36-50\end{array}$ & Continuous, leaf trait \\
\hline $\begin{array}{l}\text { Maximum petiole } \\
\text { length }(\mathrm{PeL})\end{array}$ & $\begin{array}{l}\text { Short }=45-120 \mathrm{~cm} \\
\text { medium }=121-225 \mathrm{~cm} \\
\text { long }=226-330 \mathrm{~cm}\end{array}$ & Continuous, leaf trait \\
\hline $\begin{array}{l}\text { Maximum leaf rachis } \\
\text { length }(R L)\end{array}$ & $\begin{array}{l}\text { Short }=0-3 \mathrm{~m}, \text { medium }=3.1-7, \\
\text { Long }>7\end{array}$ & Continuous, leaf trait \\
\hline $\begin{array}{l}\text { Maximum blade } \\
\text { length }(B L)\end{array}$ & $\begin{array}{l}\text { Short }=0-5 \mathrm{~m} \text {, medium }=5.1-10 \\
\text { long }>10\end{array}$ & Continuous, leaf trait \\
\hline $\begin{array}{l}\text { Average fruit width } \\
\text { (FrW) }\end{array}$ & $\begin{array}{l}\text { Thin }<=2.4 \mathrm{~cm}, \\
\text { medium }=2.5-4.2, \text { wide }=>4.3\end{array}$ & $\begin{array}{l}\text { Continuous, } \\
\text { reproductive trait }\end{array}$ \\
\hline $\begin{array}{l}\text { Average fruit length } \\
\text { (FrL) }\end{array}$ & $\begin{array}{l}\text { Short }=0-3 \mathrm{~cm}, \text { medium }=3.1-6 \\
\text { Long }>6\end{array}$ & $\begin{array}{l}\text { Continuous, } \\
\text { reproductive trait }\end{array}$ \\
\hline $\begin{array}{l}\text { Fruit conspicuicence } \\
\text { (FrCo) }\end{array}$ & $\begin{array}{l}\text { Conspicuous = cons, } \\
\text { cryptic = cryp }\end{array}$ & $\begin{array}{l}\text { Categorical, } \\
\text { reproductive trait }\end{array}$ \\
\hline
\end{tabular}

the inundated forest (Inun, Figure 2D). Of all individuals, 50\% had short petioles $(45-120 \mathrm{~cm}$, Figure $2 \mathrm{E})$, which were more abundant in forests on $\mathrm{PrH}$. Moreover, most individuals (57 and $63 \%$, respectively) had short leaf rachises $(0-3 \mathrm{~m})$ and blades $(0-$ $5 \mathrm{~m})$, and were better represented in forest growing on white sand (WhS; Figure 2F).

Most individuals had unarmed stems and leaves (85 and $79 \%$, respectively), with a high proportion of palms with armed leaves in inundated forests (Inun; Figures 2G,H). Fruit size were evenly distributed between the forest types and most individuals had small fruits $(<2.4 \mathrm{~cm}$; Figure 2I). Most individuals $(65 \%)$ had cryptic fruits.

\section{Soil Gradients and Flooding Regime}

The PCA summarizes the 12 environmental variables (11 soil variables) with two axes generated (Figure 3) explained 43 and $20 \%$, respectively. PC1 described a gradient negatively related to $\mathrm{pH}, \mathrm{K}^{+}, \mathrm{BS}, \mathrm{Ca}^{2+}, \mathrm{ECEC}$, and $\mathrm{Mg}^{2+}$. The second axis (PC2) mainly described $\mathrm{Al}^{3+}$, acidity, and $\mathrm{Na}^{+}$(Table 2). Essentially, PC1 is a fertility gradient and PC2 is an acidity gradient.

\section{Palm Functional Trait-Environmental Variables Relationship}

The palms that present both growth forms (acaulescent and erect) were positively correlated with $\mathrm{pH}, \mathrm{K}^{+}, \mathrm{BS}, \mathrm{Ca}^{2+}, \mathrm{Mg}^{2+}$ and negatively correlated with $\mathrm{Al}^{3+}$ and acidity. That is, on fertile soils there is a greater number of palms that have both acaulescent and erect growth forms, and in the same way the number of these palms decreases in soils with high $\mathrm{Al}^{3+}$ content. The cespitose life form (LF.ces) was also correlated with $\mathrm{Na}^{+}$, which indicates that the cespitose palms increase their abundance in soils with high concentrations of this cation.

In relation to vegetative traits, we found that leaf blade length (BL) was positively correlated with ECEC. The positive correlation between armed leaves (LAr) and $\mathrm{Na}^{+}$indicates that the number of palms with armed leaves increases in soils with high sodium concentration. Presence of unarmed leaves (LAr.unar) were positively correlated with non-flooded forests (FT.nin).

Fruit size (FrL, FrW) was correlated with soil variables (Figure 4). Palms with large fruits are abundant in soils with high contents of $\mathrm{K}^{+}, \mathrm{BS}, \mathrm{Ca}^{2+}, \mathrm{ECEC}, \mathrm{Mg}^{2+}$ and in basic soils with high $\mathrm{pH}$ values. We found a negative correlation between the $\mathrm{Al}^{3+}$ in soil and fruit size (FrL, FrW) indicating that smallfruited palms are dominant in soils with low $\mathrm{Al}^{3+}$ concentration. In soils with a high content of $\mathrm{P}$, most individuals had cryptic fruits (FrCo.cryp), with colors such as brown, black, green, blue, cream, gray, ivory, straw-colored, white, or purple.

\section{DISCUSSION}

The patterns found in our analysis shows a first approximation to the understanding of the environmental mechanisms that explain the distribution of palm species in the Amazon. The causal interpretation of the results that may not necessarily reflect underlying mechanisms that govern the distribution of species in the different soil types, and that it may be necessary to analyze other variables involved such as phylogeny and intraspecific variation of the species. However, we found a primary soil fertility gradient and a secondary $\mathrm{Al}^{3+}$ and acidity gradient (Figure 3) correlated to the functional traits. This pattern has been found in other studies (Fyllas et al., 2012; Liu et al., 2012). The gradient goes from the terra firme soils Ninu and white sand forests that are more sterile to the flooded forests with a high content of nutrients. Previous research has shown that plant traits vary predictably along soil gradients on a regional and global scale (Ordoñez et al., 2009). In general, the results show that palms with large leaves and fruits and acaulescent and erect growth forms are associated with fertile soils. In contrast, leaves and stems armed traits are associated with noninundated environments (Figure 5). These results suggest that the functional traits of palms vary consistently along with the soil gradients on a regional scale and that this variation could be explained by the soil fertility and acidity plus $\mathrm{Al}^{3+}$ gradients, suggesting an environmental filter related to resource availability and stressful environments such as acid and high aluminum content soils. These results on a regional scale are reported here for the first time for palms and represent the basis for additional specific studies of the significant correlations found between morphological functional traits and soil variables, which permits the elucidation of underlying mechanisms of the structuring of palm communities in Amazonia, incorporating functional dimension of the biodiversity.

Previous studies have shown an increase in the values of foliar traits (leaf area and specific leaf area) on fertile 


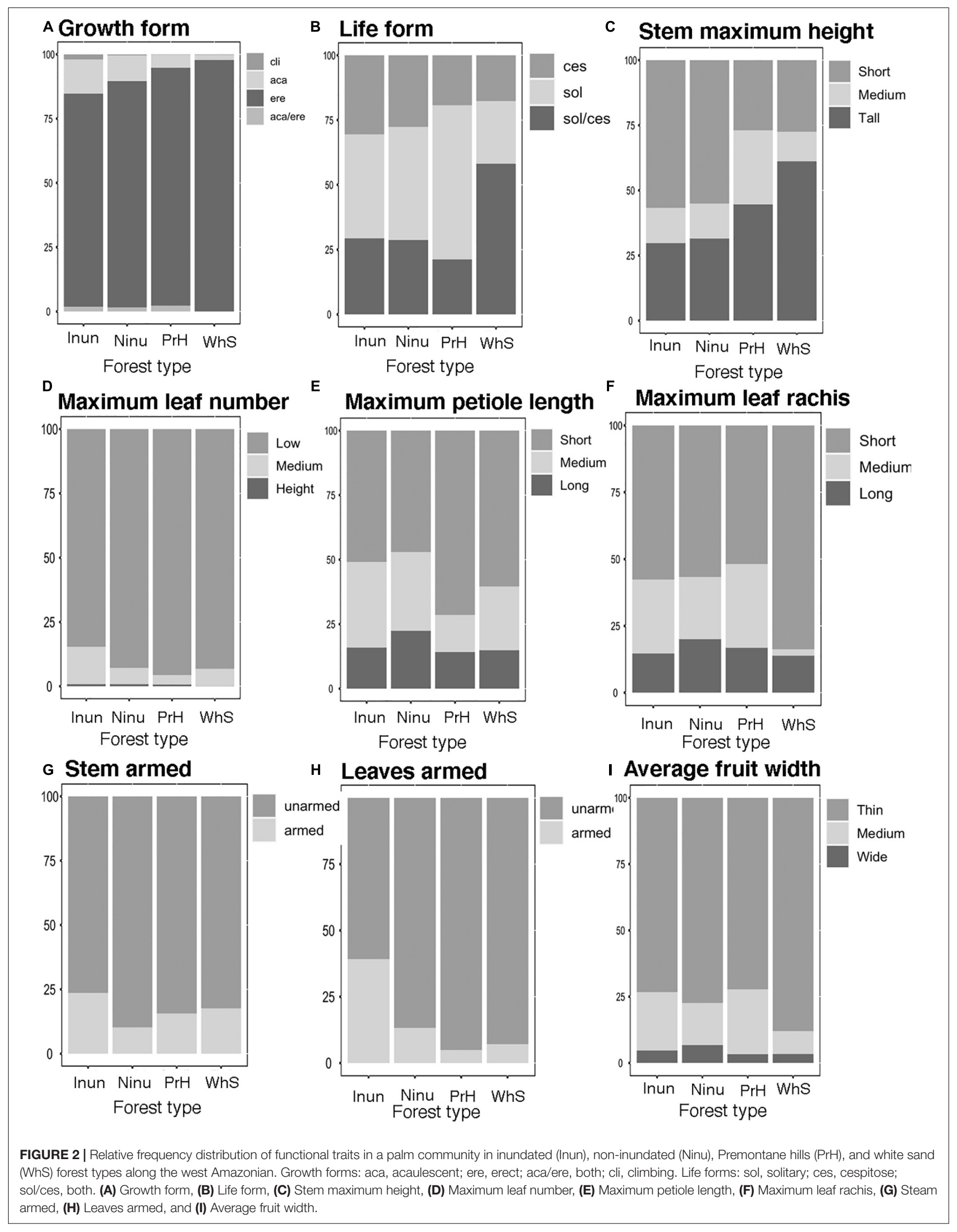


TABLE 2 | Correlations between soil variables and the two axes generated from principal component analysis.

\begin{tabular}{lrr}
\hline Variable & PC1 & PC2 \\
\hline $\mathrm{pH}$ & $-\mathbf{0 . 3 5 8}$ & 0.173 \\
$\mathrm{loi}$ & -0.106 & $-\mathbf{0 . 3 4 5}$ \\
$\mathrm{Al}^{3+}$ & 0.205 & $-\mathbf{0 . 4 5 3}$ \\
$\mathrm{K}^{+}$ & $-\mathbf{0 . 3 6 5}$ & -0.062 \\
$\mathrm{acidity}$ & 0.028 & $-\mathbf{0 . 4 9 9}$ \\
$\mathrm{BS}$ & $-\mathbf{0 . 3 7 1}$ & 0.228 \\
$\mathrm{Ca}{ }^{2+}$ & $-\mathbf{0 . 4 1 6}$ & 0.022 \\
$\mathrm{Na}^{+}$ & -0.184 & $-\mathbf{0 . 3 2 1}$ \\
$\mathrm{P}$ & -0.172 & -0.110 \\
$\mathrm{ECEC}^{+}$ & $-\mathbf{0 . 3 3 4}$ & -0.309 \\
$\mathrm{Mg}^{2+}$ & $-\mathbf{0 . 4 0 1}$ & -0.116 \\
\hline
\end{tabular}

PC1, Axis 1; PC2, Axis 2.

Bold values are the highest correlations.

soils. The average leaf area of trees in tropical forests in Panama is related to the fertility and acidity of the soil (Liu et al., 2012). For palms, the specific leaf area (SLA) increased through a gradient of nutrient availability in the soil (Andersen et al., 2012). We found that leaf size (BL, RL) increases with $\mathrm{Ca}^{2+}, \mathrm{Mg}^{2+}$, and ECEC. Species with high leaf area and SLA values have relatively high photosynthetic and respiration rates, associated with an acquisitive strategy (Wright and Westoby, 2002; Cornelissen et al., 2003; Sterck et al., 2006).

The biotic factors that determine fruit size have been extensively studied, mainly under hypotheses of dispersal syndromes (Gautier-Hion et al., 1985) in which the presence and type of dispersers exert selective pressure on the fruit size. For palms, small-conspicuous fruits are dispersed by birds, and large-cryptic fruits are dispersed by large mammals (do Nascimento et al., 2020). We found, on a regional scale, a correlation of soil fertility with fruit size. Some studies of other angiosperms have shown a weak relationship between the fruit size and disperser availability. On the other hand, they demonstrated that abiotic factors such as light availability in the canopy are more strongly correlated with fruit size (Eriksson et al., 2000). It has been suggested that large seeds have less dispersal capacity and require suitable environments to germinate due to their low possibility of moving (do Nascimento et al., 2020). Producing large fruits and seeds is costly for the plant (Goheen et al., 2007), but large seeds often have a greater chance of germination (Galetti et al., 2013). In this sense, the functional dominance of large fruits in fertile soils, found in this study, can be explained in part by the requirement of the palms to find soils with abundant resources that allow them to compensate the dispersal limitations and the cost of producing large fruits.

Additionally, the PCA analysis shows a fertility gradient in which flooded forests have more fertile soils than nonflooded forests (Figure 5), showing an indirect association of both environmental variables. Some studies in varzea and igapo forests in central Amazonia have demonstrated that species with large seeds are adapted to areas with high levels of flooding by promoting rapid seedling establishment (Parolin et al., 2003). Other studies have found contrasting results where species with large seeds are abundant in less fertile soils (Liu et al., 2012). These results are adapted to the hypothesis that suggests that species with low values of seed mass are expected to be located in soils with low nutrient levels (Liu et al., 2012). In low resource environments, large seeds could provide more reserves for individuals early in their life cycle. Small seeds have the potential advantage of greater dispersal ability and rapid growth in high-resource environments (Westoby et al., 1996). Additional studies of palms are necessary to evaluate alternative mechanisms in this regard.

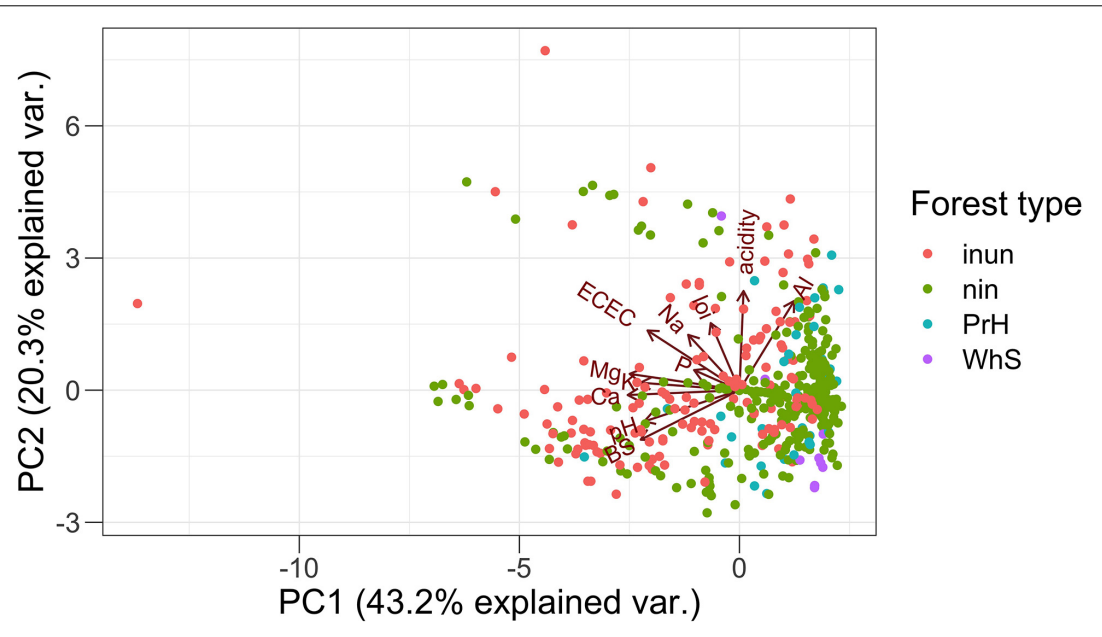

FIGURE 3 | PCA of environmental variables in the 458 transects in western Amazonia. local environmental variables: inun, inundated forest; nin, non-inundated forest; PrH, premontane hills; and WhS, white sand forest. Soil variables: pH, loi, loss-on-ignition; Al, aluminum concentration; K, Potassium concentration; acidity, exchangeable acidity; BS, base saturation; Ca, Calcium concentration; Na, Sodium concentration; P, Phosphorus concentration; ECEC, effective cation exchange capacity; and Mg, Magnesium concentration. 


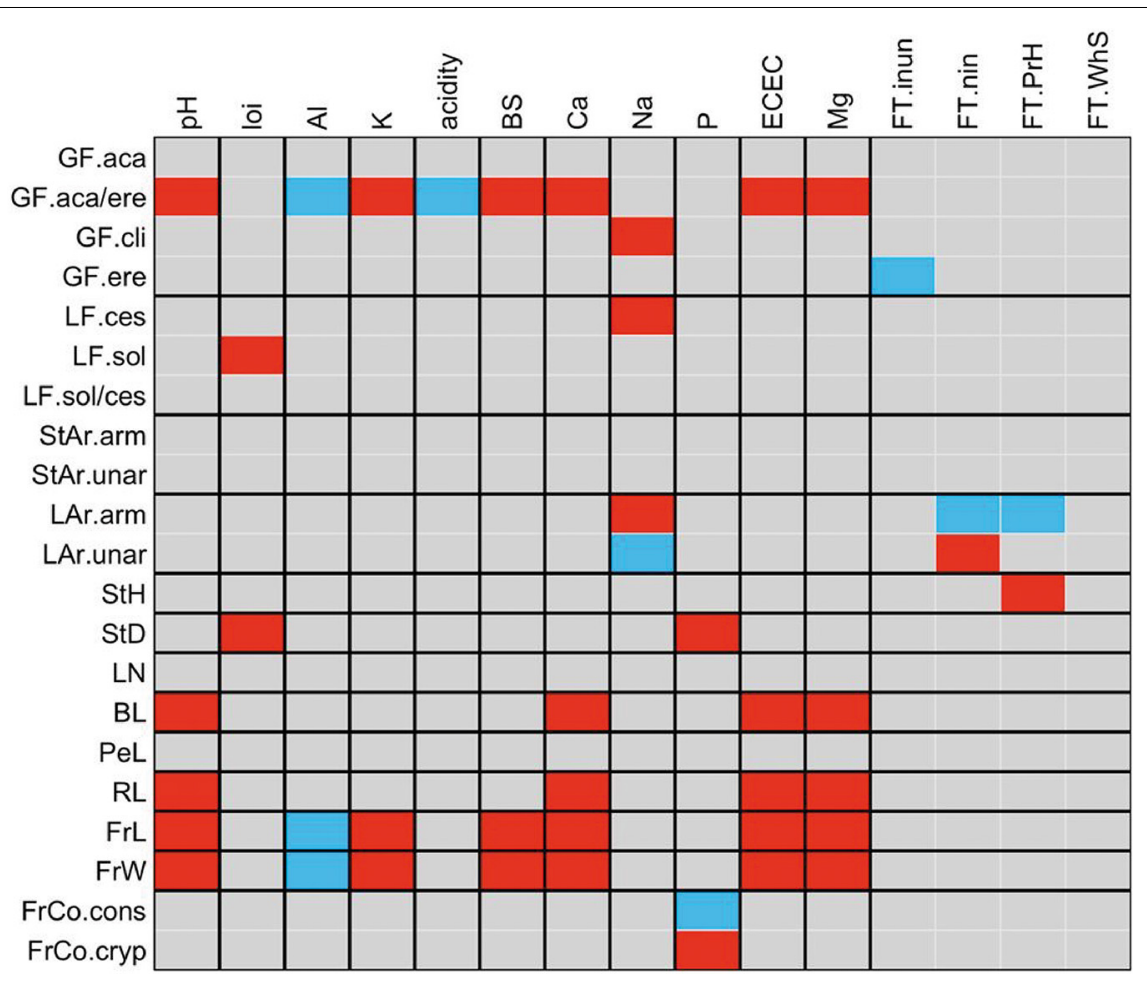

FIGURE 4 | Fourth-corner analysis carried out for functional traits of palm and environmental variables. Colored squares show significant correlations $(P<0.05)$ measured by a Pearson correlation coefficient for two quantitative variables, by a Pearson $\chi^{2}$ and $G$ statistic for two qualitative variables and by a Pseudo- $F$ and Pearson $r$ for one quantitative variable and one qualitative variable. Red, positive correlation and blue, negative correlation. local environmental variables; FT.inun, inundated forest; FT.nin, non-inundated forest; FT.PrH, premontane hills and FT. WhS, white sand forest. Soil variables: pH, loi, loss-on-ignition; Al, aluminum concentration; K, Potassium concentration; acidity, exchangeable acidity; BS, base saturation; Ca, Calcium concentration; Na, Sodium concentration; $\mathrm{P}$, Phosphorus concentration; ECEC, effective cation exchange capacity, and Mg, Magnesium concentration.

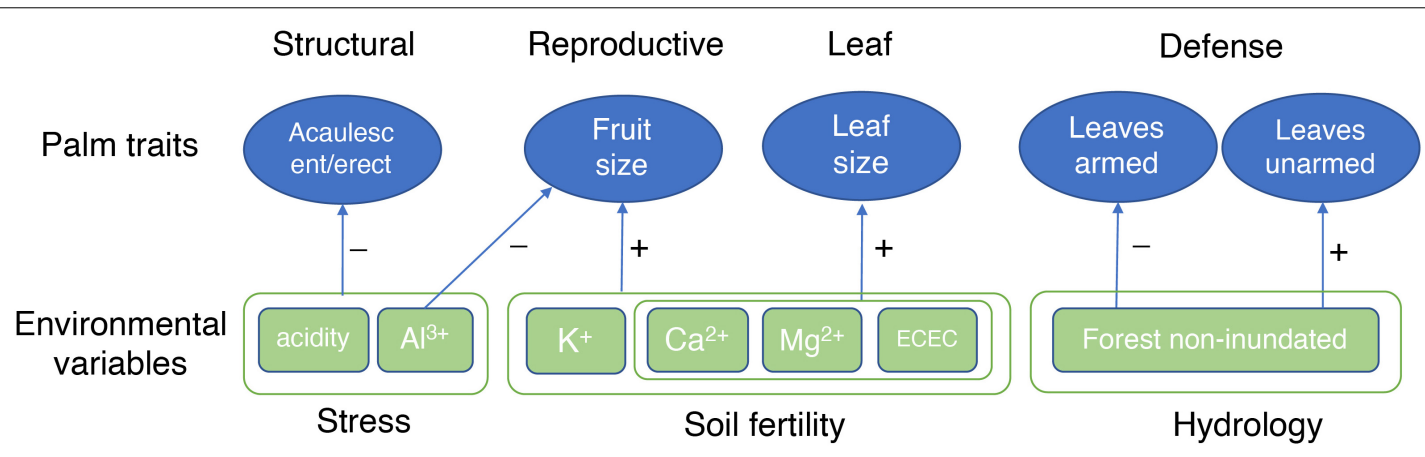

FIGURE 5 | Summary of the palm traits-environment correlations for the 116 palm species present in western Amazonia.

Hydrology has been reported to be a driver of community composition and distribution of palm species only on a local scale and not on a regional scale (Eiserhardt et al., 2011). In this work, we found that the functional composition, at least in growth form, is also scale-dependent since we did not find a correlation between the acaulescent growth form and flooding forest when using all our data from western Amazonia. However, when analyzing subregions separately, we found that the acaulescent growth form was significantly correlated with terra firme forests in Brazil and Guaviare. That is, the acaulescent palms are abundant on terra firme and absent in flooded forests. Tall palm is a functional response to prevent leaves and leaf buds from becoming submerged, making survival and growth in flooded zones possible. Therefore, it is an evasion strategy to avoid anoxic effects caused by water (Garssen et al., 2015). Spatial scale is central to geographical ecology (Levin, 1992) because patterns and processes in ecological systems are scale-dependent (Pearson and Dawson, 2003) this may influence patterns and underlying drivers of species diversity. Previous studies have found that the inundation regime is an essential determinant of palm species 
richness on a landscape scale, at least in the presence of sizeable hydrological variation, as is the case in Amazonia. However, it is obvious that in $\mathrm{PrH}$, the inundation regimens were different because the topography is more pronounced.

Regarding defense traits, the presence of spines is a conspicuous feature of many palm species in western Amazonia. The presence, type, size, and density of spines play a role in anti-herbivore defense, which may act against different potential herbivores, mostly vertebrates (Cornelissen et al., 2003). It is possible that armed palms are not an ecological response to flooding, as there is no evidence that herbivory increases in flooded areas. One possible explanation is that large fruits and defensive structures evolved simultaneously because large frugivores such as the extinct megafauna, in addition to consuming fruits and dispersing seeds, could also have consumed leaves and damaged plants (do Nascimento et al., 2020). Producing spines constitutes resource allocation costs to plants (Goheen et al., 2007), whereby resources that otherwise would be devoted to growth or reproduction are used to produce defensive structures. In this sense, it appears reasonable to suggest that because floodplain forests are more fertile than terra firme, palms prefer environments with high amounts of nutrients in the soil that allow them to compensate for the expense invested in defense structures. Additional research to elucidate this correlation and reveal alternative mechanisms of these functional groups would be pertinent to show the structuring of communities on a regional scale.

\section{CONCLUSION}

Life form, fruit size, and leaf size were positively correlated with soil fertility. Defense traits (armed leaves and stems) were correlated with hydrology (non-inundated forests). This suggests that the functional traits of palms vary consistently along soil gradients on a regional scale and that this variation could be explained by the soil fertility and acidity + aluminum gradients, suggesting environmental filters related to resource availability and stressful environments.

In this study, it is reported for first time for palms that, as well as the composition and distribution of species, the functional

\section{REFERENCES}

Andersen, K. M., Endara, M. J., Turner, B. L., and Dalling, J. W. (2012). Trait-based community assembly of understory palms along a soil nutrient gradient in a lower montane tropical forest. Oecologia 168, 519-531. doi: 10.1007/s00442011-2112-Z

Andersen, K. M., Turner, B. L., and Dalling, J. W. (2010). Soil-based habitat partitioning in understorey palms in lower montane tropical forests. J. Biogeogr. 37, 278-292. doi: 10.1111/j.1365-2699.2009.02192.x

Balslev, H., Kristiansen, S. M., and Muscarella, R. (2019). Palm community transects and soil properties in western Amazonia. Ecology 100:e02841. doi: 10.1002/ecy. 2841

Baribault, T. W., Kobe, R. K., and Finley, A. O. (2012). Tropical tree growth is correlated with soil phosphorus, potassium, and calcium, though not for legumes. Ecol. Monogr. 82, 189-203. doi: 10.1890/11-1013.1

Borchsenius, F., and Bernal, R. (1996). Aiphanes (Palmae). New York: The New York Botanical Garden. composition is scale-dependent and that possibly some traits such as growth form respond differently on a local scale than on a regional scale. Likewise, large leaves of palms on fertile soils mean a competitive strategy that confers a competitive advantage to maximize growth. Large fruits in fertile soils do not suggest a conservative strategy and instead, the results may be due to large fruits having less dispersal capacity and requiring suitable environments to germinate. Because the production of spines constitutes resource allocation costs to plants, palms prefer environments with high amounts of nutrients in the soil that allow them to compensate for the expense invested in defense structures. The results found here, enhance the need to deepen the study of morphological and physiological aspects of palms, in such a way that a greater understanding of their response to the complexity and environmental variability in the Amazon will be achieved.

\section{DATA AVAILABILITY STATEMENT}

The datasets presented in this study can be found in online repositories. The names of the repository/repositories and accession number(s) can be found below: https://doi.org/10. 1002/ecy.2841.

\section{AUTHOR CONTRIBUTIONS}

HB collected the data. WT, CR-R, and HB contributed to conception and design of the study and wrote sections of the manuscript. WT organized the database and wrote the first draft of the manuscript. WT and CR-R performed the statistical analysis. All authors contributed to manuscript revision, read, and approved the submitted version.

\section{FUNDING}

Funding was received Danish Council for Independent Research - Natural Sciences (grants \#4181-00158 and \#9040$00136 \mathrm{~B}$ to $\mathrm{HB})$.

Cámara, R., Tuomisto, H., Ruokolainen, K., Balslev, H., and Munch Kristiansen, S. (2017). Modelling responses of western Amazonian palms to soil nutrients. J. Ecol .105, 367-381. doi: 10.1111/1365-2745. 12708

Clark, D. A., Clark, D. B., Sandoval, R., and Castro, M. (1995). Edaphic and human effects on landscape-scale distributions of tropical rain forest palms. Ecology 76, 2581-2594. doi: 10.2307/2265829

Condit, R., Engelbrecht, B. M., Pino, D., Pérez, R., and Turner, B. L. (2013). Species distributions in response to individual soil nutrients and seasonal drought across a community of tropical trees. PNAS 110, 5064-5068. doi: 10.1073/pnas. 1218042110

R Core Team. (2016). R: a Language and Environment for Statistical Computing. Vienna: R Foundation for Statistical Computing.

Cornelissen, J. H., Lavorel, S., Garnier, E., Diaz, S., Buchmann, N., Gurvich, D. E., et al. (2003). A handbook of protocols for standardised and easy measurement of plant functional traits worldwide. Aust. J. Bot. 51, 335-380. doi: 10.1071/ BT02124 
De Deyn, G. B., Cornelissen, J. H. C., and Bardgett, R. D. (2008). Plant functional traits and soil carbon sequestration in contrasting biomes. Ecol. Lett. 11, 516-531. doi: 10.1111/j.1461-0248.2008.01164.x

Díaz, S., Kattge, J., Cornelissen, J. H., Wright, I. J., Lavorel, S., Dray, S., et al. (2016). The global spectrum of plant form and function. Nature 529, 167-171. doi: 10.1038/nature16489

do Nascimento, L. F., Guimarães, P. R., Onstein, R. E., Kissling, W. D., and Pires, M. M. (2020). Associated evolution of fruit size, fruit colour and spines in Neotropical palms. J. Evol. Biol. 33, 858-868. doi: 10.1111/jeb.1 3619

Dray, S., Choler, P., Dolédec, S., Peres-Neto, P. R., Thuiller, W., Pavoine, S., et al. (2014). Combining the fourth-corner and the RLQ methods for assessing trait responses to environmental variation. Ecology 95, 14-21. doi: 10.1890/130196.1

Dray, S., and Dufour, A. B. (2007). The ade4 package: implementing the duality diagram for ecologists. J. Stat. Softw. 22, 1-20.

Eiserhardt, W. L., Svenning, J. C., Borchsenius, F., Kristiansen, T., and Balslev, H. (2013). Separating environmental and geographical determinants of phylogenetic community structure in Amazonian palms (Arecaceae). Bot. J. Linn. Soc. 17, 244-259. doi: 10.1111/j.1095-8339.2012. 01276.x

Eiserhardt, W. L., Svenning, J. C., Kissling, W. D., and Balslev, H. (2011). Geographical ecology of the palms (Arecaceae): determinants of diversity and distributions across spatial scales. Ann. Bot. 108, 1391-1416. doi: 10.1093/aob/ mcr146

Eriksson, O., Friis, E. M., and Löfgren, P. (2000). Seed size, fruit size, and dispersal systems in angiosperms from the Early Cretaceous to the Late Tertiary. Amer. Natural. 156, 47-58. doi: 10.1086/303367

Fortunel, C., Garnier, E., Joffre, R., Kazakou, E., Quested, H., Grigulis, K., et al. (2009). Leaf traits capture the effects of land use changes and climate on litter decomposability of grasslands across Europe. Ecology 90, 598-611. doi: 10.1890/ 08-0418.1

Fyllas, N. M., Quesada, C. A., and Lloyd, J. (2012). Deriving plant functional types for Amazonian forests for use in vegetation dynamics models. Perspect. Plant Ecol. Evol. Syst. 14, 97-110. doi: 10.1016/j.ppees.2011.11.001

Galeano, G., and Bernal, R. (2010). Palmas de Colombia: guía de Campo. Bogotá: Universidad Nacional de Colombia.

Galetti, M., Guevara, R., Cortes, M. C., Fadini, R., Von Matter, S., Leite, A. B., et al. (2013). Functional extinction of birds drives rapid evolutionary changes in seed size. Science 340, 1086-1090. doi: 10.1126/science.1233774

Garssen, A. G., Baattrup-Pedersen, A., Voesenek, L. A., Verhoeven, J. T., and Soons, M. B. (2015). Riparian plant community responses to increased flooding: a meta-analysis. Glob. Change Biol. 21, 2881-2890. doi: 10.1111/gcb. 12921

Gautier-Hion, A., Duplantier, J. M., Quris, R., Feer, F., Sourd, C., Decoux, J. P., et al. (1985). Fruit characters as a basis of fruit choice and seed dispersal in a tropical forest vertebrate community. Oecologia 65, 324-337.

Goheen, J. R., Young, T. P., Keesing, F., and Palmer, T. M. (2007). Consequences of herbivory by native ungulates for the reproduction of a savanna tree. J. Ecol. 95, 129-138. doi: 10.1111/j.1365-2745.2006.01196.x

Grigulis, K., Lavorel, S., Krainer, U., Legay, N., Baxendale, C., Dumont, M., et al. (2013). Relative contributions of plant traits and soil microbial properties to mountain grassland ecosystem services. J. Ecol. 101, 47-57. doi: 10.1111/13652745.12014

Henderson, A. (2000). Bactris (Palmae). New York: The New York Botanical Garden.

Jordano, P. (2000). "Fruits and frugivory" in Seeds: the Ecology of Regeneration in Plant Communities, . ed. M. Fenner UK: Commonwealth Agricultural Bureau International. 125-166.

Kahn, F., and Ferreira, E. J. L. (1995). A new species of Astrocaryum (Palmae) from Acre, Brazil. Candollea 50, 321-328.

Kahn, F., and Millán, B. (2013). Las Palmeras Huicungo. Perú: Universidad Mayor de San Marcos.

Keddy, P. A. (1992). Assembly and response rules: two goals for predictive community ecology. J. Veg. Sci. 3, 157-164. doi: 10.2307/3235676

Kissling, W. D., Balslev, H., Baker, W. J., Dransfield, J., Göldel, B., Lim, J. Y., et al. (2019). PalmTraits 1.0, a species-level functional trait database of palms worldwide. Sci. Data 6, 1-13. doi: 10.1038/s41597-019-0189-0
Kristiansen, T., Svenning, J. C., Pedersen, D., Eiserhardt, W. L., Grández, C., and Balslev, H. (2011). Local and regional palm (Arecaceae) species richness patterns and their cross-scale determinants in the western Amazon. J. Ecol. 99, 1001-1015. doi: 10.1111/j.1365-2745.2011.01834.x

Laughlin, D. C., Richardson, S. J., Wright, E. F., and Bellingham, P. J. (2015). Environmental filtering and positive plant litter feedback simultaneously explain correlations between leaf traits and soil fertility. Ecosystems 18, 12691280. doi: 10.1007/s10021-015-9899-0

Lavorel, S., and Garnier, E. (2002). Predicting changes in community composition and ecosystem functioning from plant traits: revisiting the Holy Grail. Funct. Ecol. 16, 545-556. doi: 10.1046/j.1365-2435.2002.00664.x

Legay, N., Baxendale, C., Grigulis, K., Krainer, U., Kastl, E., Schloter, M., et al. (2014). Contribution of above- and below-ground plant traits to the structure and function of grassland soil microbial communities. Ann. Bot. 114, 10111021. doi: 10.1093/aob/mcu169

Levin, S. A. (1992). The problem of pattern and scale in ecology. Ecology $y^{*} .73$, 1943-1967.

Liu, X., Swenson, N. G., Wright, S. J., Zhang, L., Song, K., Du, Y., et al. (2012). Covariation in plant functional traits and soil fertility within two species-rich forests. PLoS One 7:e34767. doi: 10.1371/journal.pone.003 4767

Maire, V., Wright, I. J., Prentice, I. C., Batjes, N. H., Bhaskar, R., Bodegom, P. M., et al. (2015). Global effects of soil and climate on leaf photosynthetic traits and rates. Glob. Ecol Biogeogr. 24, 706-717. doi: 10.1111/geb.12296

Moles, A. T., Warton, D. I., Warman, L., Swenson, N. G., Laffan, S. W., Zanne, A. E., et al. (2009). Global patterns in plant height. J. Ecol. 97, 923-932. doi: 10.1111/j.1365-2745.2009.01526.x

Oksanen, J., Blanchet, F. G., Kindt, R., Legendre, P., Minchin, P. R., O’hara, R. B., et al. (2013). Package 'vegan'. Community Ecol. 2, 1-295.

Ordoñez, J. C., Van Bodegom, P. M., Witte, J. P., Wright, I. J., Reich, P. B., and Aerts, R. (2009). A global study of relationships between leaf traits, climate and soil measures of nutrient fertility. Glob. Ecol. Biogeogr. 18, 137-149. doi: 10.1111/j.1466-8238.2008.00441.x

Parolin, P., Ferreira, L., and Junk, W. (2003). Germination characteristics and establishment of trees from Central Amazonian flood plains. Trop. Ecol. 44, 155-168.

Pearson, R. G., and Dawson, T. P. (2003). Predicting the impacts of climate change on the distribution of species: are bioclimate envelope models useful? Glob. Ecol. Biogeogr. 12, 361-371. doi: 10.1046/j.1466-822X.2003.00042.x

Phillips, O. L., Vargas, P. N., Monteagudo, A. L., Cruz, A. P., Zans, M. E., Sánchez, W. G., et al. (2003). Habitat association among Amazonian tree species: a landscape-scale approach. J. Ecol. 91, 757-775. doi: 10.1046/j.1365-2745.2003. 00815.x

Reich, P. B. (2014). The world-wide 'fast-slow' plant economics spectrum: a traits manifesto. J. Ecol. 102, 275-301. doi: 10.1111/1365-2745.12211

Silman, M. R. (2007). "Plant species diversity in Amazonian forests" in Tropical Rainforest Responses to Climatic Change*,. eds M. B. Bush and J. R. Flenley Germany: Springer. 269-294.

Sombroek, W. (2000). Amazon landforms and soils in relation to biological diversity. Acta Amaz. 30, 81-100. doi: 10.1590/1809-43922000301100

Sterck, F. J., Poorter, L., and Schieving, F. (2006). Leaf traits determine the growthsurvival trade-off across rain forest tree species. Am. Nat. 167, 758-765. doi: $10.1086 / 503056$

Tuomisto, H., Ruokolainen, K., Aguilar, M., and Sarmiento, A. (2003a). Floristic patterns along a 43-km long transect in an Amazonian rain forest. J. Ecol. 91, 743-756. doi: 10.1046/j.1365-2745.2003.00802.x

Tuomisto, H., Ruokolainen, K., and Yli-Halla, M. (2003b). Dispersal, environment, and floristic variation of western Amazonian forests. Science 299, 241-244. doi: 10.1126/science.1078037

Van der Putten, W. H., Bardgett, R. D., Bever, J. D., Bezemer, T. M., Casper, B. B., Fukami, T., et al. (2013). Plant-soil feedbacks: the past, the present and future challenges. J. Ecol. 101, 265-276. doi: 10.1111/1365-2745. 12054

Vitousek, P. M. (1984). Litterfall, nutrient cycling, and nutrient limitation in tropical forests. Ecology 65, 285-298. doi: 10.2307/1939481

Vormisto, J., Tuomisto, H., and Oksanen, J. (2004). Palm distribution patterns in Amazonian rainforests: what is the role of topographic 
variation? J. Veg. Sci. 15, 485-494. doi: 10.1111/j.1654-1103.2004. tb02287.x

Westoby, M. (1998). A leaf-height-seed (LHS) plant ecology strategy scheme. Plant Soil 199, 213-227.

Westoby, M., Leishman, M., and Lord, J. (1996). Comparative ecology of seed size and dispersal. Phil. Trans. R. Soc. Lond. B 351, 1309-1317. doi: 10.1098/rstb. 1996.0114

Wright, I. J., Reich, P. B., Westoby, M., Ackerly, D. D., Baruch, Z., Bongers, F., et al. (2004). The worldwide leaf economics spectrum. Nature 428, 821-827. doi: $10.1038 /$ nature 02403

Wright, I. J., and Westoby, M. (2002). Leaves at low versus high rainfall: coordination of structure, lifespan and physiology. N. Phytol. 155, 403-416. doi: 10.1046/j.1469-8137.2002.00479.x

Xi, N., Adler, P. B., Chen, D., Wu, H., Catford, J. A., van Bodegom, P. M., et al. (2021). Relationships between plant-soil feedbacks and functional traits. J. Ecol. 104, 1608-1617. doi: 10.1111/1365-2745.13731
Conflict of Interest: The authors declare that the research was conducted in the absence of any commercial or financial relationships that could be construed as a potential conflict of interest.

Publisher's Note: All claims expressed in this article are solely those of the authors and do not necessarily represent those of their affiliated organizations, or those of the publisher, the editors and the reviewers. Any product that may be evaluated in this article, or claim that may be made by its manufacturer, is not guaranteed or endorsed by the publisher.

Copyright (c) 2021 Trujillo, Rivera-Rondón and Balslev. This is an open-access article distributed under the terms of the Creative Commons Attribution License (CC BY). The use, distribution or reproduction in other forums is permitted, provided the original author(s) and the copyright owner(s) are credited and that the original publication in this journal is cited, in accordance with accepted academic practice. No use, distribution or reproduction is permitted which does not comply with these terms. 